\title{
COCAINE USE IN AMSTERDAM IN NON DEVIANT SUBCULTURES
}

\author{
Peter CoHen \& Arjan SAS
}




\title{
Cocaine Use in Amsterdam in Non Deviant Subcultures*
}

\author{
Peter Cohen, Ph.D. \\ Senior Researcher \\ Universiteit van Amsterdam, Faculteit Ruimtelijke Wetenschappen, Vakgroep Sociale Geografie, Nieuwe \\ Prinsengracht 130, $1018 \mathrm{VZ}$ Amsterdam \\ tel: 02052542 78,fax: 02052540 51, email:pcohen@popmail.ic.uva.nl,http://www.frw.uva.nl/acd/isg/drugs/ \\ Arjan Sas \\ Researcher \\ Universiteit van Amsterdam, Faculteit Ruimtelijke Wetenschappen, Vakgroep Sociale Geografie, Nieuwe \\ Prinsengracht 130, $1018 \mathrm{VZ}$ Amsterdam \\ tel: 02052540 61, fax: 02052540 51, email:arjansas@euronet.nl,http://www.frw.uva.nl/acd/isg/drugs/
}

\section{Abstract}

Cocaine use was studied in Amsterdam among experienced users not drawn from biased populations of treatment clients, prison inmates, or prostitutes, but from the much larger pool of community based cocaine users. Cocaine use was studied in two samples, 160 in 1987 and 108 in 1991, recruited using snowball sampling techniques. Sixty-four of the 1987 respondents were also reinterviewed in 1991. Data gathered in these three investigations primarily focus on the effects and consequences of cocaine use, circumstances of use, development of level of use, and rules applied to cocaine use in general. The largest single group of users (50\%) never exceed a low use level (less than .5 grams a week). About one in five progress to a high use level of 2.5 grams a week or more during their top period of use. Sustained high level use is rare. There are clear indications that experienced cocaine users tend to diminish their use over time, lace it with periods of abstention, and adjust it primarily to social functions. Negative effects are prevented by a series of rules surrounding use, although no user escapes the occurrence of negative effects altogether.

In Amsterdam we studied cocaine use in three different projects between 1987 and 1991. Our first study in 1987 consisted of 160 in depth interviews with experienced users (Cohen 1989). In the second study we interviewed 64 of these four years later in 1991 (Cohen and Sas 1993). Also in 1991 we interviewed 108 'new users' with the same interview instrument as in 1987. New users were those who started regular use after 1986 (Cohen and Sas 1994, forthcoming). In the following contribution we will first explain the methodological design of these studies, and then some of the major outcomes.

* With gratitude to Ernest Drucker, Ph.D. (New York), Harm 't Hart, Ph.D. (Utrecht) and Lana Harrison Ph.D. (Washington) for their helpful remarks on an earlier version of this paper. 


\section{Methodology}

Since much is known about cocaine use in convenience samples from prison inmates, treatments clients or hot line callers, we decided to look for community based users. We wanted to recruit cocaine users via a 'snowball' methodology, outside institutions in the field of drug control and treatment. We wanted to know which effects and consequences of cocaine use would become visible with persons who are mainstream citizens or as close to that social stratum as possible. ${ }^{1}$ Parallel to our line of not wanting cocaine users from classic convenience populations, we also did not want to recruit first snowball contacts among highly deviant and easy to find sub groups like prostitutes, so called junkies ${ }^{2}$ and full time criminals / prisoners. We feared such deviant lifestyles would contaminate and complicate our findings about the impact of cocaine on life events.

In 1987, entry criterion for experienced cocaine users into the study was a minimum lifetime experience of 25 occasions of use. Our first contacts were cocaine users known to the research staff and to the interviewers of the Bureau that executed the field work. These first contacts, not being junkies, full time criminals or prostitutes, were asked to list initials, gender and age of not more than 20 cocaine users known to them. From this list two potential respondents were randomly selected by the interviewer. ${ }^{3}$ The nominating respondent was asked to contact the first nominee, establish their willingness to participate, and ask for permission to give full name and address to the interviewer. After (rare) refusal or people not honoring their appointments (less rare) we would turn to the second nominee. Initial instructions were to abandon a list of nominees after two unsuccessful referrals. Later this was expanded to four. By means of this snowballing method we interviewed 160 experienced cocaine users.

In 1991, our goal was to find 120 'new users' of a later generation, who initiated cocaine use when the substance had a more negative association. Our 1991 study required at least 10 occasions of use after 1986. (Still, 78\% had used more often than 25 times). Our first contacts were established mainly by requests in the press (written, radio and TV), by asking our followup respondents, and by independent search by our interviewers. Our new user study yielded 108 interviews of respondents that started first regular cocaine use after 1986.

\begin{tabular}{|c|c|c|c|c|}
\hline \multirow{2}{*}{$\begin{array}{l}\text { net income per } \\
\text { month }\end{array}$} & \multicolumn{2}{|c|}{1987} & \multicolumn{2}{|c|}{191991} \\
\hline & $\mathrm{n}$ & $\%$ & $n$ & $\%$ \\
\hline less than $f 1,000$ & 22 & 14 & 15 & 14 \\
\hline$f 1,000-1,500$ & 54 & 34 & 38 & 35 \\
\hline$f 1,500-2,000$ & 33 & 21 & 21 & 19 \\
\hline$f 2,000-2,500$ & 17 & 11 & 13 & 12 \\
\hline$f 2,500-3,000$ & 17 & 11 & 10 & 9 \\
\hline$f 3,000-4,000$ & 10 & 6 & 7 & 6 \\
\hline$f 4,000-5,000$ & 2 & 1 & 3 & 3 \\
\hline $5,000-6,000$ & 1 & 1 & 1 & 1 \\
\hline more than $f 6,000$ & 4 & 3 & - & - \\
\hline total & 160 & 100 & 108 & 100 \\
\hline mean & & & & \\
\hline
\end{tabular}

In both years we were able to check the snowball samples against cocaine users found in completely different probability samples resulting from household studies in Amsterdam in the same years. In 1987 we compared the snowball sample of 160 with 68 cocaine users from 
the 1987 household survey who reported cocaine use in the 12 months prior to interview. ${ }^{4}$ In 1991 we compared our snowball sample with 61 users found in the 1990 household survey who reported starting cocaine use after 1985. Comparing our snowball samples on a range of variables, like age, gender, education, nationality (ethnicity), profession and income with the reference samples from the household surveys, we found no significant differences. This means that our findings in the snowball samples can be regarded as representative of community based cocaine users in Amsterdam.

Table 1b. Level of cocaine use at three periods in time in 1987 sample and in 1991 sample

\begin{tabular}{|c|c|c|c|c|c|c|c|c|c|c|c|c|}
\hline \multirow{3}{*}{$\begin{array}{l}\text { level of } \\
\text { cocaine use }\end{array}$} & \multicolumn{4}{|c|}{ first year of regular use } & \multicolumn{4}{|c|}{ period of heaviest use } & \multicolumn{4}{|c|}{ last 3 months } \\
\hline & \multicolumn{2}{|c|}{1987} & \multicolumn{2}{|c|}{1991} & \multicolumn{2}{|c|}{1987} & \multicolumn{2}{|c|}{1991} & \multicolumn{2}{|c|}{1987} & \multicolumn{2}{|c|}{1991} \\
\hline & $\mathrm{n}$ & $\%$ & $\mathrm{n}$ & $\%$ & $\mathrm{n}$ & $\%$ & $\mathrm{n}$ & $\%$ & $\mathrm{n}$ & $\%$ & $\mathrm{n}$ & $\%$ \\
\hline none & - & - & - & - & - & - & - & - & 44 & 28 & 28 & 26 \\
\hline low & 143 & 89 & 88 & 81 & 77 & 48 & 57 & 53 & 103 & 64 & 65 & 60 \\
\hline medium & 13 & 8 & 16 & 15 & 49 & 31 & 33 & 31 & 10 & 6 & 10 & 9 \\
\hline high & 4 & 3 & 2 & 2 & 33 & 21 & 17 & 16 & 3 & 2 & 4 & 4 \\
\hline unknown & - & - & 2 & 2 & 1 & 1 & 1 & 1 & - & - & 1 & 1 \\
\hline total & 160 & 100 & 108 & 100 & 160 & 100 & 108 & 100 & 160 & 100 & 108 & 100 \\
\hline Student's t & $\begin{array}{l}\mathrm{t}=-0.6 \\
\text { (separ } \\
\mathrm{F}=4.2\end{array}$ & $\begin{array}{l}d f=1 \\
\text { e vari } \\
p<0 .\end{array}$ & $\begin{array}{l}12, \mathrm{n} \text {. } \\
\text { ce est } \\
\text { 1) }\end{array}$ & & $\begin{array}{l}\mathrm{t}=-0.3 \\
\text { (separ } \\
\mathrm{F}=2.3\end{array}$ & $\begin{array}{l}\mathrm{df}=16 \\
\text { e vari } \\
\mathrm{p}<0.0\end{array}$ & $\begin{array}{l}04, n \text {. } \\
\text { ce est } \\
\text { 1) }\end{array}$ & & $\begin{array}{l}\mathrm{t}=-0.7 \\
\text { (separ } \\
\mathrm{F}=3.5\end{array}$ & $\begin{array}{l}\mathrm{df}=1 \\
\text { e vari } \\
p<0 .\end{array}$ & $\begin{array}{l}.78, n \\
\text { ice est } \\
1 \text { ) }\end{array}$ & \\
\hline
\end{tabular}

The two snowball samples were taken four years apart to see if the respondents attracted to cocaine differed in the two periods. On average, the 1987 users initiated around 1980 (when cocaine had an elite and classy image). By restricting entrance into our 1991 study to first regular use since 1986, we hoped to be able to trace possible changes in respondent demographics associated with the newer image of cocaine as a dangerous drug. We also hoped to find out if, independent of user type, use patterns changed.

We found respondents in both groups to be amazingly similar. This conclusion is based on core data on demographic and (cocaine) drug use patterns. Users in both samples are better educated than their age cohort, over $80 \%$ are between 20 and 35 years of age, unmarried, much more experienced with all illicit drugs than their age cohort and more social and outgoing. Half of all users in both samples never progressed to levels higher than 0.5 grams a week, even during periods of heaviest use. High use levels (of more than 2.5 grams a week) occur with about $20 \%$ of all users during periods of heaviest use. Such levels are rarely maintained (about $4 \%$ ) from the period of heaviest use to the time of interview. Because the original purpose of contrasting the two samples from 1987 and 1991 is not relevant for the present publication, and because of the similarity of the two snowball samples in relation to demographics and major use characteristics, we merged the findings of each snowball sample into one data set reflecting 268 cocaine users.

In this overview article we will first present the most relevant data on the 268 experienced cocaine users. To demographic and lifestyle data we will add details about cocaine use careers from initiation on and about effects and consequences of cocaine use. We will further present similar data on 64 cocaine users from the 1987 sample we followed up in 1991. We will conclude with some general remarks about cocaine use in Amsterdam, in particular about the control mechanisms that seem to play a role in how cocaine users prevent or overcome negative effects of cocaine. 


\section{Characteristics of community based cocaine users in Amsterdam}

\section{General Characteristics}

Table 2 presents data on the age of cocaine users in Amsterdam. The age of current users recruited through the snowballs do not differ from cocaine users sampled in the Amsterdam household surveys in 1987 and 1990. Cocaine use is highly age related, and rare under 20 and over 40 . More than half of all current users are between 26 and 35 years. Of these experienced users, $87 \%$ are born in the Netherlands and $57 \%$ are male.

\begin{tabular}{|c|c|c|}
\hline age & $\mathrm{n}$ & $\%$ \\
\hline under 20 years & 3 & 1.1 \\
\hline $20-25$ years & 71 & 26.5 \\
\hline 26 - 30 years & 97 & 36.2 \\
\hline 31 - 35 years & 58 & 21.6 \\
\hline $36-40$ years & 27 & 10.1 \\
\hline over 40 years & 12 & 4.5 \\
\hline total & 268 & 100.0 \\
\hline
\end{tabular}

Table 3 shows educational attainment for this sample, which is rather high. This is similar to findings for cocaine users in the household studies. Occupational activities of experienced users are varied. Large subgroups are: students at some educational institution (15\%), artists and art related occupations $(24 \%),{ }_{1}^{5}$ higher occupational strata like doctors, managers, high level administrators, higher education personnel, computer services (15\%) medium and low level occupational strata employees like nurses, handymen, hairdressers (20\%) and people working in hotel/bar / restaurant business (10\%). For $9 \%$ we have no data or no occupational background was reported. Full time or part time employment at the time of interview is reported by $60 \%$. The rest derive income from unemployment insurance benefits, scholarships, occasional work as a builder or handymen and savings or social security.

Table 3. Education of respondents

\begin{tabular}{lrr}
\hline \hline education & $\mathrm{n}$ & \multicolumn{1}{c}{$\%$} \\
\hline elementary school & 7 & 2.6 \\
low level vocational school & 6 & 2.2 \\
low level high school & 29 & 10.8 \\
medium level vocational school & 20 & 7.5 \\
medium \& high level high school & 49 & 18.3 \\
high level vocational school & 75 & 28.0 \\
university & 82 & 30.6 \\
\hline total & 268 & 100.0 \\
\hline
\end{tabular}

Table 4. Household situation of respondents

\begin{tabular}{lrr}
\hline \hline & $\mathrm{n}$ & \multicolumn{1}{c}{$\%$} \\
\hline living alone & 175 & 65.3 \\
living with partner & 69 & 25.7 \\
living with children, without partner & 6 & 2.2 \\
commune & 9 & 3.4 \\
with parents & 2 & 0.7 \\
other & 7 & 2.6 \\
\hline total & 268 & 100.0 \\
\hline
\end{tabular}

Most respondents live alone and very few have children at home. Just over $25 \%$ live with a partner in the same house, although $60 \%$ report having a partner. Experienced cocaine users are predominantly unmarried. Only $14 \%$ were ever married.

Respondent's average net income is fl 1,866 per month, ${ }^{6}$ and $20 \%$ make more than $\mathrm{fl} 2,500$ a month. The high income group, earning over $\mathrm{fl} 4,000$ per month, comprises $4 \%$ of the sample in comparison to the $14 \%$ in the low income group who earn less than $\mathrm{fl} 1,000$ per month. 
Income distribution does not differ from the age cohort in the household population. These income figures show cocaine use is by no means limited to high or low income strata, but quite evenly divided.

\section{Other Drug Use}

The experienced cocaine users we sampled in 1987 and 1991 are also experienced users of other drugs if we compare them to the household age cohort aged 18-53 (the full age range in our cocaine user samples). As shown in Table 5, almost all cocaine users have used cannabis, and just under $40 \%$ have experience with opiates and LSD.

\begin{tabular}{|c|c|c|c|c|}
\hline \multirow{2}{*}{$\begin{array}{l}\text { life time } \\
\text { prevalence of }\end{array}$} & \multicolumn{2}{|c|}{ cocaine users } & \multicolumn{2}{|c|}{ age cohort } \\
\hline & $\mathrm{n}$ & $\%$ & $\mathrm{n}$ & $\%$ \\
\hline tobacco & 260 & 97.0 & 2,094 & 71.7 \\
\hline cannabis & 248 & 92.5 & 1,043 & 35.7 \\
\hline alcohol & 263 & 98.1 & 2,584 & 88.4 \\
\hline LSD & 103 & 38.4 & 177 & 6.1 \\
\hline opiates (incl. licit) & 102 & 38.1 & 239 & 8.2 \\
\hline hypnotics & 73 & 27.2 & 590 & 20.2 \\
\hline sedatives & 70 & 26.1 & 476 & 16.3 \\
\hline ether & 24 & 9.0 & 40 & 1.4 \\
\hline MDMA* & 68 & 63.0 & 55 & 1.9 \\
\hline amphetamines* & 62 & 57.4 & 178 & 6.1 \\
\hline cocaine & 268 & 100.0 & 241 & 8.2 \\
\hline $\begin{array}{l}\text { * Data on LTP of } M \\
\text { cocaine users are } \\
(\mathrm{N}=108)\end{array}$ & & & $N$ us & \\
\hline
\end{tabular}

\section{Cocaine Use}

\section{Initiation and Level of Use through Time}

The average age of initiation into cocaine use is 22.2 years, although a sizable proportion $(33.2 \%)$ initiate prior to 20 years. Almost one quarter of the sample (23.7\%) first used cocaine when they were over 25 years of age, but an initiation age of over 35 is rare (2.6\%). On average, our respondents have a career of 7 years since initiation (range 0.5 - 21 years) and of 5 years since first regular use of cocaine (range 0.5 - 20 years).

To show how the level of cocaine use develops during the period between the first year of regular use and the interview we adopted a technique first used by Chitwood (1985). Level of use is defined in grams per week. We computed level of use by multiplying reported frequency of use with the normal number of lines used (assuming $25 \mathrm{mg}$. per line) in a particular period. Low level is defined as 0.5 gram per week or less, medium level between 0.5 and 2.5 grams per week and high level as use over 2.5 grams per week.

Table 6 shows the proportion of users at each level of use, at three different moments in their career. Half never exceed 0.5 grams per week, the other half does during their period of heaviest use. As shown in both Table 6 and Figure 1, medium and high level use do not last. At the time of the interview many are abstinent, irrespective of their use level at the period of heaviest use. ${ }^{7}$ This means that the level of use, even at its heaviest period, does not predict the probability of abstinence. 
Table 6. Level of cocaine use in three periods

\begin{tabular}{|c|c|c|c|c|c|c|}
\hline \multirow[b]{2}{*}{ level of use } & \multicolumn{2}{|c|}{$\begin{array}{l}\text { first year of } \\
\text { regular use }\end{array}$} & \multicolumn{2}{|c|}{$\begin{array}{c}\text { period of } \\
\text { heaviest use }\end{array}$} & \multirow{2}{*}{$\begin{array}{c}\text { last } 3 \\
\text { prior to } \\
n\end{array}$} & \multirow{2}{*}{$\begin{array}{c}\text { months } \\
\text { interview } \\
\%\end{array}$} \\
\hline & $\mathrm{n}$ & $\%$ & $\mathrm{n}$ & $\%$ & & \\
\hline none & - & - & - & - & 71 & 26.5 \\
\hline low & 232 & 86.6 & 134 & 50.0 & 168 & 62.7 \\
\hline medium & 29 & 10.8 & 82 & 30.6 & 20 & 7.5 \\
\hline high & 5 & 1.9 & 50 & 18.7 & 7 & 2.6 \\
\hline unknown & 2 & 0.7 & 2 & 0.7 & 2 & 0.7 \\
\hline total & 268 & 100.0 & 268 & 100.0 & 268 & 100.0 \\
\hline
\end{tabular}

Figure 1 gives insight into the dynamics of use: it shows cocaine use shifting from one level to another through time, both in upward and downward directions. It also shows which respondents remain static in terms of our defined use levels.

In Table 7, the large differences between use level categories can be seen. The group that consumes most during their top period has a median consumption of $1000 \mathrm{mg}$. a day, versus $20 \mathrm{mg}$. a day in the low level group. The range between low level users and high level users during their top period is enormous, from $10 \mathrm{mg}$. to $42000 \mathrm{mg}$. a week.

The average duration of the top period of low level users ( 16 months) is almost a year less than the average top period of high level users (26 months). Still, even at high level of use, 50\% report that their top period is 18 months or less. A very clear correlation exists between the

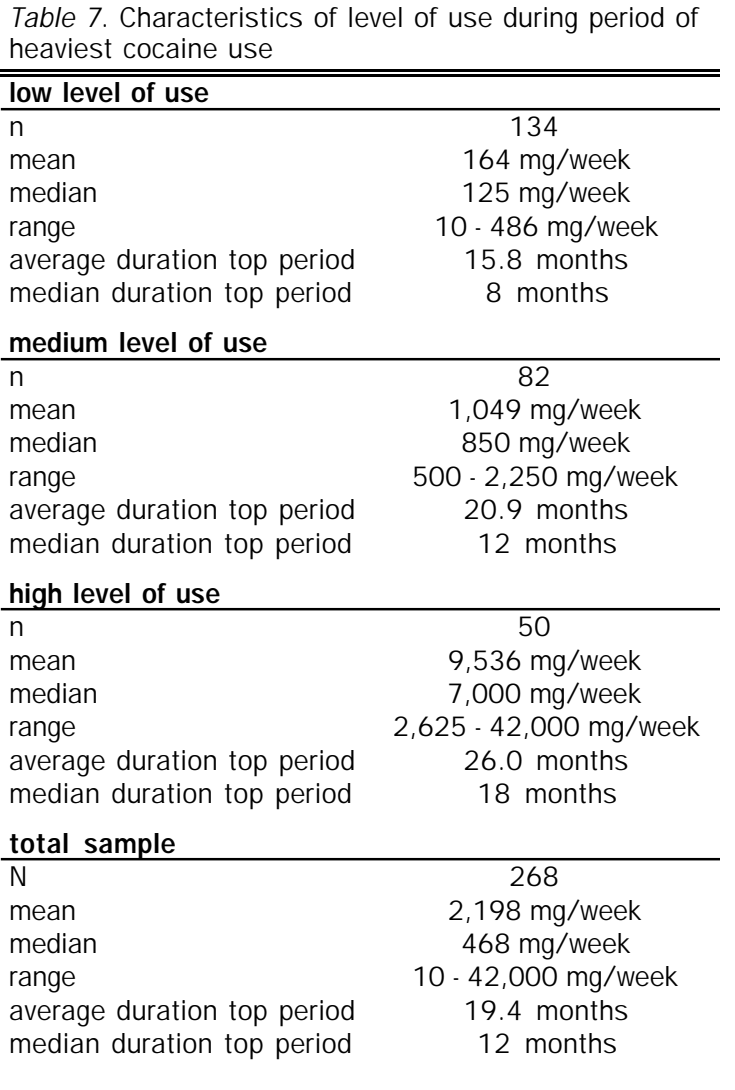


Figure 1. Level of cocaine use over time (number of respondents between brackets, $\mathrm{N}=268$ )

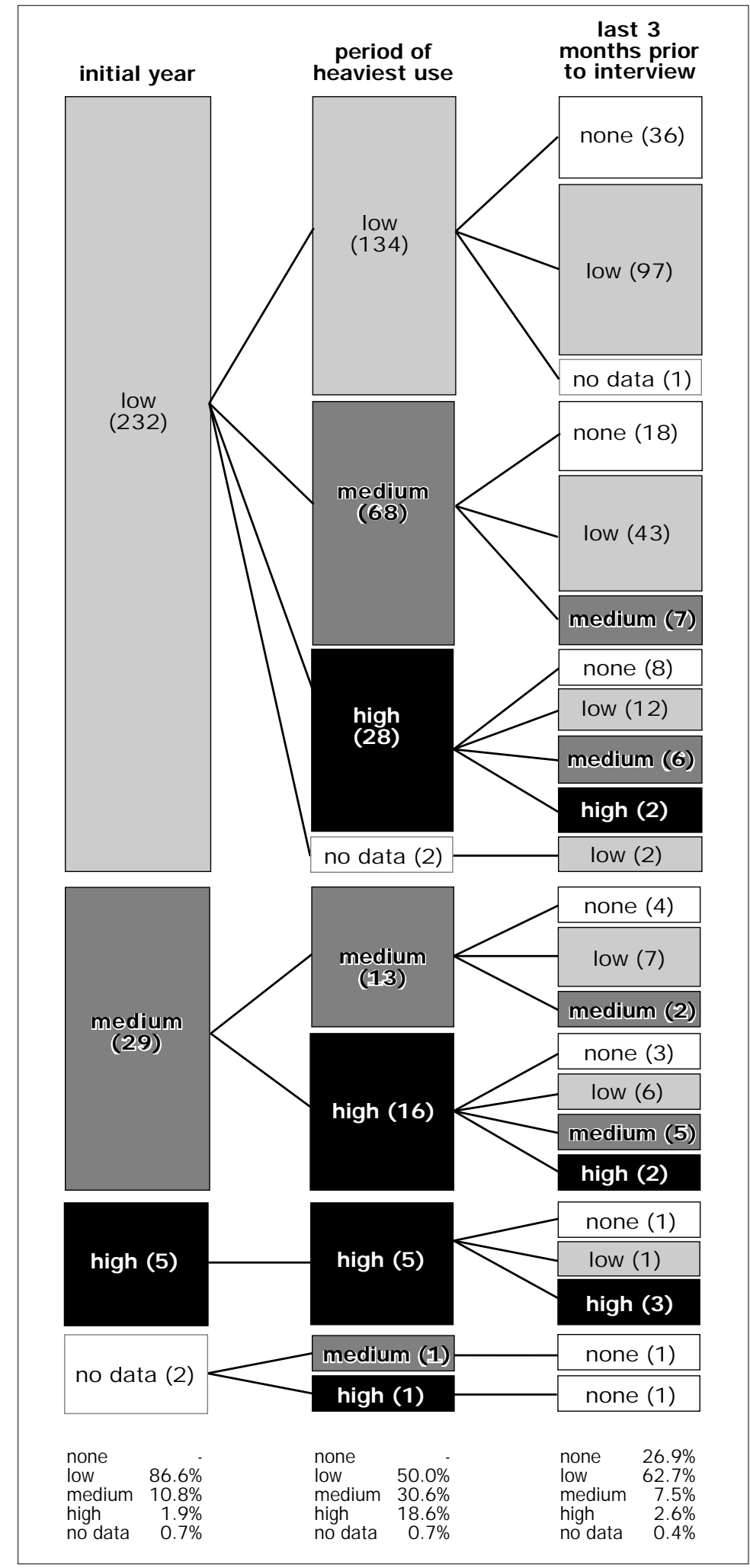


length of top period and level of use. It is difficult to say why. High level users experience many more adverse effects from cocaine than other users. Do they value the positive effects more? We observed however that the proportion of high level users who end up abstinent is no smaller than for other users.

Table 8 shows how median dosage at normal occasions of use moves from $100 \mathrm{mg}$. during the first year of regular use, to $250 \mathrm{mg}$. during the top period, and then to $125 \mathrm{mg}$. during the three months prior to interview. ${ }^{8}$ The route of ingestion of these users is principally intranasal: almost three-quarters (74\%) report snorting as their primary mode of use. But (lifetime) experience with other methods is widespread. In Amsterdam, 66\% have smoked cocaine hydrochloride in a cigarette mixed with tobacco, $23 \%$ have freebased, and $6 \%$ have injected. Community based cocaine users who have other routes of ingestion as their main method are rare: injecting $2 \%$, freebasing $3.5 \%$, in cigarettes $4 \% .{ }^{9}$ Methods like injecting and freebasing carry a heavy stigma of 'junky' behavior. This was most often mentioned as the reason respondents would not use these methods at all or prolong them beyond initial experimentation. Route of ingestion and the idealogy surrounding it probably are an important control mechanism.

Table 8. Dosage at a typical occasion in four periods of time

\begin{tabular}{|c|c|c|c|c|c|c|}
\hline \multirow[b]{2}{*}{ dosage } & \multicolumn{2}{|c|}{$\begin{array}{c}\text { first } \\
\text { cocaine use }\end{array}$} & \multicolumn{2}{|c|}{$\begin{array}{l}\text { first year of } \\
\text { regular use }\end{array}$} & \multicolumn{2}{|c|}{$\begin{array}{c}\text { period of } \\
\text { heaviest use }\end{array}$} \\
\hline & $\mathrm{n}$ & $\%$ & $\mathrm{n}$ & $\%$ & $\mathrm{n}$ & $\%$ \\
\hline none & - & & & - & - & - \\
\hline $1-99 \mathrm{mg}$ & 181 & 67.5 & 102 & 38.1 & 36 & 13.4 \\
\hline $100-249 \mathrm{mg}$ & 59 & 22.0 & 90 & 33.6 & 91 & 34.0 \\
\hline $250-499 \mathrm{mg}$ & 14 & 5.2 & 42 & 15.7 & 69 & 25.7 \\
\hline more than $500 \mathrm{mg}$ & 9 & 3.4 & 34 & 12.7 & 70 & 26.1 \\
\hline no answer & 5 & 1.9 & & - & 2 & 0.7 \\
\hline total & 268 & 100.0 & 268 & 100.0 & 268 & 100.0 \\
\hline mean & & $\mathrm{mg}$ & & $\mathrm{mg}$ & & $\mathrm{mg}$ \\
\hline median & & $\mathrm{mg}$ & & $\mathrm{mg}$ & & $\mathrm{mg}$ \\
\hline
\end{tabular}

\begin{tabular}{lcccc} 
& $\begin{array}{c}\text { last three months } \\
\text { zero dosage }\end{array}$ & \multicolumn{2}{c}{$\begin{array}{c}\text { prior to interview } \\
\text { included }\end{array}$} & \multicolumn{2}{c}{$\begin{array}{c}\text { zerosage } \\
\text { excluded }\end{array}$} \\
dosage & $\mathrm{n}$ & $\%$ & $\mathrm{n}$ & $\%$ \\
\hline none & 59 & 22.0 & & \\
$1-99 \mathrm{mg}$ & 66 & 24.6 & 66 & 31.6 \\
$100-249 \mathrm{mg}$ & 73 & 27.2 & 73 & 34.9 \\
$250-499 \mathrm{mg}$ & 37 & 13.8 & 37 & 17.7 \\
more than $500 \mathrm{mg}$ & 21 & 7.8 & 21 & 10.0 \\
no answer & 12 & 4.5 & 12 & 5.7 \\
\hline total & 268 & 100.0 & 209 & 100.0 \\
\hline mean & $178 \mathrm{mg}$ & $207 \mathrm{mg}$ \\
median & $100 \mathrm{mg}$ & $125 \mathrm{mg}$
\end{tabular}

Weekend use is the most important mode with low level users. With rare exception all high level users took cocaine daily during their period of heaviest use. Many users lace their cocaine use career with periods of abstention. Such periods may last from a week to several months. We asked only for abstention periods of one month or longer. A minority report no such periods (14\%), and another minority report rare occurrence of such periods of one or two times $(18 \%)$. Two thirds $(66 \%)$ report three or more of such periods (Table 9 ).

There were many reasons for such periods of abstention. We divided these reasons into internal and external ones. Of the internal reasons most often mentioned was "no desire for 


\begin{tabular}{|c|c|c|}
\hline & $\mathrm{n}$ & $\%$ \\
\hline never & 38 & 14.2 \\
\hline 1 or 2 times & 49 & 18.3 \\
\hline 3 - 5 times & 47 & 17.5 \\
\hline $6-10$ times & 42 & 15.7 \\
\hline more than 10 times & 88 & 32.8 \\
\hline unknown & 4 & 1.5 \\
\hline total & 268 & 100.0 \\
\hline
\end{tabular}

cocaine." This reason was given by 40 respondents (18\% of all mentioned reasons). The next reason for periods of abstention was occurrence of negative mental or physical effects mentioned by 21 respondents ( $9 \%$ of all reasons). Fear of dependence was mentioned by 11 respondents ( $5 \%$ of all reasons). The most important external reason was 'no money' given by 43 respondents (19\% of all reasons). External reasons that refer to context (friends do not use, no suitable environment for use) account for 37 answers, or $16 \%$ of all answers. Other reasons are pregnancy (3), work or study (5), or trips to foreign countries (8).

When asked if respondents have ever cut back on their use, just over $60 \%$ answer affirmatively. This very high percentage was surprising against a backdrop of $50 \%$ of all respondents never exceeding a use level of 0.5 grams a week. The most important reasons for cutting back were the same as for periods of abstinence. Of the internal reasons, the most important was no desire for cocaine (with 30 respondents). Next in importance were negative mental or physical effects (26 respondents). Of the external reasons, no money was again the most important (46 respondents) and contextual reasons followed with 22 respondents.

\section{Effects, Advantages and Disadvantages of Cocaine}

We measured effects in two ways: 1) by asking our respondents to mention the most important advantages and disadvantages of cocaine, and 2) by referring to almost a hundred different effects taken from the literature, and asking respondents if they ever experienced them as a consequence of their cocaine use. One of our goals was to find out which effects depend on dosage and / or level of use. Comparing data on level of use and its relation to effect prevalence with similar data from other studies (Erickson, 1987; Morningstar and Chitwood, 1983), we found agreement, but also some disagreement (Cohen 1989, p 99). ${ }^{10}$ Where we found a statistical covariance between level of use and prevalence of effects in Amsterdam, similar covariance was not found elsewhere, or vice versa. We also found that many effects are interrelated. We established this by creating Mokken scales of the effects by computing scalability of a large number of effects. ${ }^{11}$ It was possible to construct five scales. It seems that users report typical clusters of effects. In order to sketch a proper background of this finding we will discuss two main difficulties of effect-measurement.

One of the reasons we concluded that effects are difficult to study is our finding that variance on scale-scores was hardly explained by parameters of use. The occurrence or prevalence of effects clearly is related to many more variables than use level or dosage alone. As Lindesmith observed: "The sensation or experience varies greatly depending upon the person, the setting, the mood of the user, and the size of the dose and the manner in which it is taken" (Lindesmith, 1968). Although this quote describes Lindesmith's findings about heroin, they are probably just as applicable to cocaine or any other psychotropic substance. All these variables may 
again be superimposed upon systematic variation per location, historical period, supply situation, concomitant use of other drugs etc. Thus it becomes comprehensible that simple one-dimensional parameters of use fail to explain the variation in scores of our cocaine effect scales. ${ }^{12}$ Good effect measurement should take into account the multiple determinants of drug experience, something we are not yet able to do. ${ }^{13}$

Another problem is the reliability of the effects measurement instrument. In our follow-up study we asked the same effect questions to the same respondents four years later. On scales I and IV, we found $53 \%$ of users to score the same, but on scale III only $12 \%$, on scale V $21 \%$, and on scale II $32 \%$. Even more troublesome is that respondents also reported less effects, ranging per scale from $18 \%$ less effects to $44 \%$. This shows that the effect measuring instrument we used may be of questionable reliability. Scores on the effects scales computed via prevalence questions for each effect might be sensitive to a lot of 'noise'. This noise may consist of set and setting related variables mentioned above that influence the prevalence of certain effects, but also may include things like forgetting or suppressing the memory of certain effects.

When we compared the distribution of scores on each of the scales between the 1987 sample and the 1991 sample, we found no statistically significant differences. Because of all the other data that support our conclusion that there is a large degree of similarity between the two samples, this finding could be expected. Moreover, if our methodology of effect questioning is questionable, it would be an almost impossible feat of chance that our effect scales result in highly similar scores and score differentiation per sample. Therefore, we assume for the time being that our effect questions and their elaboration into Mokken-scales do have some kind of validity, but that the reliability of our scores per respondent is as yet not understood. Leaving these difficulties as they are we will now present some of the data on effects, advantages and disadvantages.

Table 10. Five most mentioned advantages and disadvantages of cocaine, rank order and frequency

\begin{tabular}{lccccccc}
\hline \hline \multirow{2}{*}{$\begin{array}{l}\text { advantages } \\
\text { of cocaine }\end{array}$} & 1 & 2 & 3 & 4 & $5 *$ & total & $\begin{array}{c}\text { rank order } \\
\text { total }\end{array}$ \\
\hline more energetic & 65 & 64 & 45 & 10 & 6 & 190 & 1 \\
communication & 33 & 45 & 37 & 11 & 5 & 131 & 2 \\
high, relaxed & 38 & 43 & 18 & 7 & - & 106 & 3 \\
more creative & 37 & 19 & 18 & 8 & - & 82 & 4 \\
selfconfidence & 27 & 28 & 12 & 5 & 1 & 73 & 5 \\
\hline & & & & & & & rank order \\
disadvantages & 1 & 2 & 3 & 4 & $5 *$ & total & total \\
of cocaine & 32 & 32 & 29 & 10 & 2 & 105 & 1 \\
\hline unpleasant physical effects & 29 & 23 & 26 & 9 & 1 & 88 & 2 \\
expensive & 23 & 23 & 13 & 3 & - & 62 & 3 \\
bad for health & 16 & 15 & 7 & 5 & 3 & 46 & 4 \\
makes egocentric, introverted & 20 & 13 & 6 & 2 & 1 & 42 & 5 \\
creates psych. dependence & 20 & \multicolumn{7}{c}{ order } \\
* The 1987-respondents were allowed to mention five disadvantages, the 1991-respondents four.
\end{tabular}

We found that these experienced users mention many more different disadvantages of cocaine than advantages. A part from almost uncodable idiosyncratic answers, users report 9 main categories of advantages versus 22 of disadvantages. We list only the five most important ones. As previously mentioned, we tried to measure the lifetime prevalence (LTP) of almost 100 different effects of cocaine. Table 11 contains the LTP of ten well known and 
highly undesirable adverse consequences and effects of cocaine, broken down by level of use. We see that anxiety, being overly suspicious, and tightness in chest are the effects with the highest LTP of these ten. Still, not even half of all respondents mention these effects. But most of these effects are clearly related to level of use in Amsterdam.

We found no significant difference in LTP of these effects when controlling for route of ingestion. We hypothesized that LTP of these ten negative effects would be lower if we computed them for cocaine snorters only. For some effects a lower LTP can be observed, e.g. hemorrhages have a LTP of $6 \%$ with snorters only, and of $13 \%$ when all experience with other routes of ingestion is included. But the differences are not significant. ${ }^{14}$ This means that in our sample of experienced community based users, none of the ten negative consequences can be related to route of ingestion. Still, replication of this finding should be sought in a much larger similar sample.

Table 11. Occurrence of cocaine effects and level of use in top period for respondents who exclusively snorted cocaine and for all respondents

\begin{tabular}{|c|c|c|c|c|c|c|c|c|c|}
\hline \multirow[b]{3}{*}{ effect of cocaine } & \multicolumn{8}{|c|}{ level of use during period of heaviest use } & \multirow{3}{*}{$\begin{array}{c}\chi^{2} \\
\text { significance }\end{array}$} \\
\hline & \multicolumn{2}{|c|}{ low } & \multicolumn{2}{|c|}{ medium } & \multicolumn{2}{|c|}{ high } & \multicolumn{2}{|c|}{ total } & \\
\hline & $\mathrm{n}$ & $\%$ & $\mathrm{n}$ & $\%$ & $\mathrm{n}$ & $\%$ & $\mathrm{n}$ & $\%$ & \\
\hline haemorrhages & 2 & 2 & 4 & 8 & 2 & 6 & 8 & 4 & $\sim$ \\
\hline depressions & 7 & 6 & 4 & 8 & 8 & 24 & 19 & 10 & $p<0.01$ \\
\hline anxiety & 28 & 25 & 20 & 38 & 17 & 52 & 65 & 33 & $p<0.025$ \\
\hline overly suspicious & 31 & 28 & 23 & 43 & 20 & 61 & 74 & 37 & $p<0.005$ \\
\hline spasms & 23 & 21 & 12 & 23 & 13 & 39 & 48 & 24 & $p<0.10$ \\
\hline unconciousness & 4 & 4 & 1 & 2 & 6 & 18 & 11 & 6 & $p<0.005$ \\
\hline panic & 17 & 15 & 8 & 15 & 18 & 55 & 43 & 22 & $p<0.001$ \\
\hline tightness in chest & 32 & 29 & 17 & 32 & 20 & 61 & 69 & 35 & $p<0.005$ \\
\hline violence & 8 & 7 & 4 & 8 & 5 & 15 & 17 & 9 & ns \\
\hline urge to carry weapons & 1 & 1 & 1 & 2 & 10 & 30 & 12 & 6 & $\sim$ \\
\hline & \multicolumn{2}{|c|}{$\mathrm{N}=111$} & \multicolumn{2}{|c|}{$\mathrm{N}=53$} & \multicolumn{2}{|c|}{$\mathrm{N}=33$} & \multicolumn{2}{|c|}{$\mathrm{N}=198$} & \\
\hline
\end{tabular}

all respondents

\begin{tabular}{|c|c|c|c|c|c|c|c|c|c|}
\hline \multirow[b]{3}{*}{ effect of cocaine } & \multicolumn{8}{|c|}{ level of use during period of heaviest use } & \multirow{3}{*}{$\begin{array}{c}\chi^{2} \\
\text { significance }\end{array}$} \\
\hline & \multicolumn{2}{|c|}{ low } & \multicolumn{2}{|c|}{ medium } & \multicolumn{2}{|c|}{ high } & \multicolumn{2}{|c|}{ total } & \\
\hline & $\mathrm{n}$ & $\%$ & $\mathrm{n}$ & $\%$ & $\mathrm{n}$ & $\%$ & $\mathrm{n}$ & $\%$ & \\
\hline haemorrhages & 3 & 2 & 4 & 6 & 6 & 13 & 13 & 5 & $\sim$ \\
\hline depressions & 11 & 7 & 8 & 12 & 10 & 21 & 29 & 11 & $p<0.025$ \\
\hline anxiety & 43 & 28 & 26 & 38 & 25 & 53 & 94 & 35 & $p<0.01$ \\
\hline overly suspicious & 43 & 28 & 29 & 43 & 30 & 64 & 102 & 38 & $p<0.001$ \\
\hline spasms & 29 & 19 & 14 & 21 & 20 & 43 & 63 & 24 & $p<0.005$ \\
\hline unconciousness & 5 & 3 & 2 & 3 & 11 & 23 & 18 & 7 & $p<0.001$ \\
\hline panic & 21 & 14 & 12 & 18 & 25 & 53 & 58 & 22 & $p<0.001$ \\
\hline tightness in chest & 45 & 30 & 25 & 37 & 31 & 66 & 101 & 38 & $p<0.001$ \\
\hline violence & 12 & 8 & 8 & 12 & 8 & 17 & 28 & 10 & ns \\
\hline urge to carry weapons & 1 & 1 & 2 & 3 & 16 & 34 & 19 & 7 & $p<0.001$ \\
\hline & \multicolumn{2}{|c|}{$\mathrm{N}=152$} & \multicolumn{2}{|c|}{$\mathrm{N}=68$} & \multicolumn{2}{|c|}{$N=47$} & \multicolumn{2}{|c|}{$\mathrm{N}=268$} & \\
\hline
\end{tabular}

The list of adverse effects shows that for some, cocaine can be malicious. A lifetime prevalence of $7 \%$ for cocaine induced unconsciousness is not exceedingly high, but dramatic for the few with whom it occurs. ${ }^{15}$ Panic attacks have a lifetime prevalence of $22 \%$ in this group, and the well known tightness in the chest occurs with $38 \%$. Depressions, so often popularly associated with cocaine, has a surprisingly low LTP of $11 \%$. It is not among the five most frequently 
mentioned disadvantages, and is mentioned by only 29 persons (11\%). Just sixteen persons $(6 \%)$ mention depressions as the most important disadvantage of cocaine.

It is clear that the probability of some adverse effects of cocaine can be lowered by lowering ones use level. This undoubtedly is a major reason why so few high level users maintain this level. As reported earlier, negative mental and physical effects were given as important reasons for a period of abstention or cut back on use level. None of these adverse effects have a zero LTP, even with low level users.

Of respondents who in 1987 attributed the urge to carry weapons to cocaine, $36 \%$ had a conviction for a felony in the two years prior to interview. Of those who did not report this urge, only $6 \%$ were convicted of a felony. Reporters of this urge had almost all committed at least oneillegal act to obtain cocaine $(91 \%)$ in comparison to $27 \%$ whonever reported this urge. We suspect that the urge to carry weapons is related to more lifestyle determinants than cocaine use per se. ${ }^{16}$

We asked these experienced cocaine users if cocaine had ever been an obsession for them. Thirty five percent answered affirmatively. Almost all $(80 \%)$ report they sometimes felt a strong desire (longing, in Dutch) for cocaine.

\section{Loss of Control}

In order to measure loss of control with cocaine, we designed a 'loss of control scale' based on a long list of items. Since we have an abundance of data from each experienced cocaine user we interviewed, we assembled a multi-item operationalization of the concept 'loss of control'.

Table 12. Item list for the loss of control scale, weight, maximum score and score per item

\begin{tabular}{|c|c|c|c|c|}
\hline \multirow[b]{2}{*}{ item } & \multicolumn{4}{|c|}{ maximum } \\
\hline & weight & score & $\mathrm{n}$ & $\%$ \\
\hline cocaine ever an obsession & 1 & 1 & 94 & 35.1 \\
\hline taking extra job to buy cocaine & 1 or $3^{\circ}$ & 3 & 9 & 3.4 \\
\hline borrowing money to buy cocaine & 1 or $3^{\circ}$ & 3 & 14 & 5.2 \\
\hline selling personal possessions to by cocaine & 1 or $3^{\circ}$ & 3 & 13 & 4.9 \\
\hline stealing from family of friends & 1 or $3^{\circ}$ & 3 & 5 & 1.9 \\
\hline shoplifting to buy cocaine & 1 or $3^{\circ}$ & 3 & 7 & 2.6 \\
\hline burglary to buy cocaine & 1 or $3^{\circ}$ & 3 & 4 & 1.5 \\
\hline theft (face to face) to buy cocaine & 1 or $3^{\circ}$ & 3 & 1 & 0.4 \\
\hline forging cheques to buy cocaine & 1 or $3^{\circ}$ & 3 & 8 & 3.0 \\
\hline stealing cocaine & 1 or $3^{\circ}$ & 3 & 2 & 0.7 \\
\hline engaging in prostitution to buy cocaine & 1 or $3^{\circ}$ & 3 & 6 & 2.2 \\
\hline running con games to buy cocaine & 1 or $3^{\circ}$ & 3 & 8 & 3.0 \\
\hline car breaking to buy cocaine & 1 or $3^{\circ}$ & 3 & 2 & 0.7 \\
\hline trading sexual favors for cocaine & 1 or $3^{\circ}$ & 3 & 6 & 2.2 \\
\hline had difficulty decreasing cocaine use & 3 & 3 & 30 & 11.2 \\
\hline daily use during first year of use* & 1 & 1 & 4 & 1.5 \\
\hline daily use during period of heaviest use** & 1 & 1 & 76 & 28.4 \\
\hline daily use during the last three months prior to interview & 1 & 1 & 8 & 3.0 \\
\hline cocaine ever being the cause of divorce & 1 & 1 & 34 & 12.7 \\
\hline general increase of cocaine use during career & 1 & 1 & 17 & 6.3 \\
\hline never experienced periods of abstinence & 1 & 1 & 38 & 14.2 \\
\hline cocaine being considered as "addictive" & 3 and $3 \cdot$ & 6 & 55 & 20.5 \\
\hline experienced more than ten adverse effects of cocaine & 2 & 2 & 77 & 28.7 \\
\hline total maximum score & & 57 & & \\
\hline \multicolumn{5}{|c|}{$\begin{array}{l}\text { * In the } 1991 \text { survey we asked for the frequency of use in } 1987 \text { in stead of their first year of use. } \\
\text { ** In the } 1991 \text { survey we asked for the frequency of use in the period of heaviest use after } 1987 . \\
\text { o If the respondent reported this item having occurred three to ten times he or she got one point on the } \\
\text { scale. It it happened more than ten times he or she got three points. } \\
\text { - If the respondent considered cocaine being either physically or mentally addictive he or she got three } \\
\text { points on the scale. If cocaine was considered being both physically and mentally addictive he or she got six } \\
\text { points. }\end{array}$} \\
\hline
\end{tabular}


Table 13. Comparison of respondents who score zero and who score 8 points or more on the loss of control scale

\begin{tabular}{|c|c|c|c|c|}
\hline \multirow[b]{3}{*}{ age } & \multicolumn{4}{|c|}{ score on loss of control scale } \\
\hline & \multicolumn{2}{|c|}{ zero } & \multicolumn{2}{|c|}{8 or more } \\
\hline & $\mathrm{n}$ & $\%$ & $\mathrm{n}$ & $\%$ \\
\hline under 20 years & 1 & 1.2 & - & \\
\hline $20-25$ years & 21 & 24.4 & 5 & 16.7 \\
\hline $26-30$ years & 38 & 44.2 & 12 & 40.0 \\
\hline 31 - 35 years & 18 & 20.9 & 9 & 30.0 \\
\hline $36-40$ years & 6 & 7.0 & 3 & 10.0 \\
\hline over 40 years & 2 & 2.3 & 1 & 3.3 \\
\hline total & 86 & 100.0 & 30 & 100.0 \\
\hline mean & & & & .1 \\
\hline median & & & & .5 \\
\hline \multicolumn{5}{|c|}{$\begin{array}{l}\text { Student's } t=-1,37 ; \text { df }=114 ; \text { n.s. (pooled variance estimate, tested on } \\
\text { unclassed data) }\end{array}$} \\
\hline sex & $\mathrm{n}$ & $\%$ & $\mathrm{n}$ & $\%$ \\
\hline $\operatorname{man}$ & 50 & 58.1 & 18 & 60.0 \\
\hline woman & 36 & 41.9 & 12 & 40.0 \\
\hline total & 86 & 100.0 & 30 & 100.0 \\
\hline \multicolumn{5}{|c|}{$\chi^{2}=0.00 ; \mathrm{df}=1 ;$ n.s. (Yates' correction) } \\
\hline education & $\mathrm{n}$ & $\%$ & $\mathrm{n}$ & $\%$ \\
\hline elementary school & - & - & 1 & 3.3 \\
\hline low level vocational school & 1 & 1.2 & 1 & 3.3 \\
\hline low level high school & 4 & 4.7 & 3 & 10.0 \\
\hline medium level vocational school & 7 & 8.1 & 4 & 13.3 \\
\hline medium \& high level high school & 10 & 11.6 & 8 & 26.7 \\
\hline high level vocational school & 32 & 37.2 & 9 & 30.0 \\
\hline university & 32 & 37.2 & 4 & 13.3 \\
\hline total & 86 & 100.0 & 30 & 100.0 \\
\hline \multicolumn{5}{|c|}{ Mann-Whitney U $=801.5 ; Z=-3.2090 ; p=0.0013$} \\
\hline marital status & $\mathrm{n}$ & $\%$ & $\mathrm{n}$ & $\%$ \\
\hline married & 2 & 2.3 & 2 & 6.7 \\
\hline divorced, widowed & 4 & 4.7 & 4 & 13.3 \\
\hline unmarried & 80 & 93.0 & 24 & 80.0 \\
\hline total & 86 & 100.0 & 30 & 100.0 \\
\hline
\end{tabular}

We will not deal here with the theoretical implications of this concept and of the item list (cf. Cohen and Sas 1992;) but simply accept this 'scale' as an operational device. Many behavioral details that are commonly taken as a possible indication of loss of control are merged in this scale. In Table 12 the item list is shown, the weight that is given to each item, and the prevalence of each item. For example, $3.4 \%$ of all respondents have in their lifetime, taken on an extra job to buy cocaine. This item counts for one point on the scale score if it occurred between 3 and 10 times, and for three points if it occurred more often than ten times. This 'weighting' of items was considered necessary by us, although the actual weight of each item, one or three, is arbitrary.

Although the maximum score obtainable on the scale theoretically is 57, the highest scored we actually measured was 23 . [Pearson $R=0.49(\mathrm{p} .<0.01$ ) between scale score and level of use (in $\mathrm{mg}$. per week) during period of heaviest use.] We used score on the loss of control scale to establish eventual differences between two categories of users. We contrasted all whose score zero on the scale with the top scorers. We found 86 respondents $(32 \%)$ with a zero score. The top scorers are 30 respondents with scores of 8 and higher, $11 \%$ of the total.

We contrasted zero score users with top scorers on age, gender, education, marital status, yes / no relation with partner, living alone or with others, income and employment status (Table 
Table 13. (continued)

\begin{tabular}{lrrrr}
\hline \hline relation with partner & $\mathrm{n}$ & $\%$ & $\mathrm{n}$ & $\%$ \\
\hline no relation with partner & 37 & 43.0 & 14 & 46.7 \\
relation, less than 1 year & 9 & 10.5 & 6 & 20.0 \\
relation, longer than 1 year & 40 & 46.5 & 10 & 33.3 \\
unknown & - & - & - & - \\
\hline total & 86 & 100.0 & 30 & 100.0 \\
\hline$\chi 2=2.521 ;$ df $=2$; n.S. & & & &
\end{tabular}

\begin{tabular}{lrrrr} 
household situation & $\mathrm{n}$ & \multicolumn{1}{c}{$\%$} & \multicolumn{1}{c}{$\mathrm{n}$} & \multicolumn{1}{c}{$\%$} \\
\hline living alone & 58 & 67.4 & 21 & 70.0 \\
living with partner & 20 & 23.3 & 6 & 20.0 \\
living with children, without partner & - & - & - & - \\
commune & 4 & 4.7 & 1 & 3.3 \\
with parents & - & - & 1 & 3.3 \\
other & 4 & 4.7 & 1 & 3.3 \\
\hline total & 86 & 100.0 & 30 & 100.0 \\
\hline$\chi^{2}$ not applicable & & & &
\end{tabular}

\begin{tabular}{|c|c|c|c|c|}
\hline income & $\mathrm{n}$ & $\%$ & $\mathrm{n}$ & $\%$ \\
\hline less than $f 1,000$ & 12 & 14.0 & 4 & 13.3 \\
\hline$f 1,000-f 1,500$ & 34 & 39.5 & 11 & 36.7 \\
\hline$f 1,500-f 2,000$ & 14 & 16.3 & 7 & 23.3 \\
\hline$f 2,000-f 2,500$ & 10 & 11.6 & 2 & 6.7 \\
\hline$f 2,500-f 3,000$ & 9 & 10.5 & 2 & 6.7 \\
\hline$f 3,000-f 4,000$ & 5 & 5.8 & 0 & - \\
\hline$f 4,000-f 5,000$ & 1 & 1.2 & 2 & 6.7 \\
\hline$f 5,000-f 6,000$ & 1 & 1.2 & 1 & 3.3 \\
\hline more than $f 6,000$ & 0 & - & 1 & 3.3 \\
\hline total & 86 & 00.0 & & 00.0 \\
\hline mean & $\mathrm{f} 1$, & & f2 & 17 \\
\hline median & $f 1,2$ & & & \\
\hline
\end{tabular}

Student's $t=-0.92 ; \mathrm{df}=36.72 ;$ n.s. (Tested on class mids, separate variance estimate, $F=2.72, p<0.001$ )

\begin{tabular}{lrrrr} 
employment & $\mathrm{n}$ & \multicolumn{1}{c}{$\%$} & \multicolumn{1}{c}{$\mathrm{n}$} & $\%$ \\
\hline full-time & 26 & 30.2 & 10 & 33.3 \\
part-time & 28 & 32.6 & 5 & 16.7 \\
unemployed & 7 & 8.1 & 9 & 30.0 \\
other (students) & 25 & 29.1 & 6 & 20.0 \\
unknown & - & - & - & - \\
\hline total & 86 & 100.0 & 30 & 100.0 \\
\hline$\chi^{2}=10.433$; df $=3 ; p<0.025$ & & & &
\end{tabular}

13). Zero score respondents have a slightly higher educational level and show somewhat less unemployment: $8 \%$ of zero score users versus 30\% of 'high' score users. But even this difference in employment is not really indicative since both groups show large majorities are employed. This way of contrasting subgroups of our respondents does not yield very meaningful results.

\section{The Follow-Up Study}

In the months January to June 1991, 40-48 months after initial interviews, we invited 64 persons we had first interviewed in 1987 to participate in a follow-up study about their cocaine consumption. Our goal was to reinterview half of the original group. Locating 80 of the original 160 was not possible. The reasons were: moving out of Amsterdam to unknown 
locations (16 persons), moving abroad (5 persons), insufficient information about original address or name (61 persons), ${ }^{17}$ refusals ( 3 persons), not responding to our invitation (8 persons) and death (3 persons). ${ }^{18}$ We therefore reinterviewed everybody we could find of our original sample, ending up with 64 follow-up respondents.

In order to find out if the follow-up respondents are a biased selection of the original sample, the 64 follow-up respondents were compared to the 96 non follow-up respondents on a number of variables as we measured them in 1987.

Table 14. Employment status of nonresponse and follow-up respondents in 1987

\begin{tabular}{lrrrr}
\hline \hline & \multicolumn{2}{c}{ non-response } & \multicolumn{2}{c}{ follow-up } \\
employment & \multicolumn{1}{c}{$\mathrm{n}$} & \multicolumn{1}{c}{$\%$} & \multicolumn{1}{c}{ n } & $\%$ \\
\hline full time & 33 & 34 & 28 & 44 \\
part time & 23 & 24 & 23 & 36 \\
none & 15 & 16 & 4 & 6 \\
other & 24 & 25 & 9 & 14 \\
no answer & 1 & 1 & - & - \\
\hline total & 96 & 100 & 64 & 100 \\
\hline$\chi 2=7.85, p<0.05, \mathrm{df}=3$ & & &
\end{tabular}

Table 15. Income of non-response and follow-up respondents in 1987

\begin{tabular}{|c|c|c|c|c|}
\hline \multirow[b]{2}{*}{ net income per month } & \multicolumn{2}{|c|}{ non-response } & \multicolumn{2}{|c|}{ follow-up } \\
\hline & $\mathrm{n}$ & $\%$ & $\mathrm{n}$ & $\%$ \\
\hline less than $f 1,000$ & 15 & 16 & 7 & 11 \\
\hline$f 1,000-1,500$ & 34 & 35 & 20 & 31 \\
\hline$f 1,500-2,000$ & 22 & 23 & 11 & 17 \\
\hline $\mathrm{f} 2,000-2,500$ & 7 & 7 & 10 & 16 \\
\hline f $2,500-3,000$ & 10 & 10 & 7 & 11 \\
\hline f $3,000-4,000$ & 4 & 4 & 6 & 9 \\
\hline$f 4,000-5,000$ & 2 & 2 & - & - \\
\hline f $5,000-6,000$ & 1 & 1 & - & - \\
\hline more than $f 6,000$ & 1 & 1 & 3 & 5 \\
\hline total & 96 & 100 & 64 & 100 \\
\hline mean & & & & \\
\hline
\end{tabular}

Student's $t=1.55$ (n.s.), $d f=158$ (test on class-mids)

We found no significant differences between the two aggregates on: cocaine use in initial year, cocaine use during top period, cocaine use during last 3 months prior to 1987 interview, other drug use (sedatives, hypnotics, cannabis, LSD,solvents, opiates), income (see Table 15), marital status, gender, age, and educational level. We did find one significant difference however. In 1987, 80\% of the follow-up respondents had some form of employment versus $58 \%$ in the non follow-up aggregate (see Table 14). In spite of the difference on this variable we consider findings of the 64 follow-up respondents as representative for the whole group of 160. We had established generalizability of the data of these 160 respondents to recent cocaine users in Amsterdam and believe that the findings of our follow-up study give a reliable image of cocaine use careers in Amsterdam, over a period of about ten years, for those who had started around 1980.

\section{Developments in Cocaine Use of Follow-up Respondents}

Our follow-up respondents were subjected in 1991 to the same very extensive interview schedule as in 1987. However, if respondents had used cocaine on less than ten occasions in the four years since 1987, most of the questions were not relevant for them. We considered such respondents as nonusers and subjected them to a much shorter interview. Out of 64 follow-up respondents, $30(47 \%)$ had become nonusers according to our definition, leaving 34 respondents (53\%) as subjects for our extended interview schedule. ${ }^{19}$ When we look at the period four weeks prior to interview in 1991, it appears that 45 (75\%) of our follow-up respondents did not use cocaine. This leaves us with a group of only 19 persons out of 64 once regular users who might still be considered as relatively regular and continuous users at follow-up.

Looking at the period of three months before follow-up interview, 22 respondents (34\%) report use. Cross tabulating their levels of use during the three months prior to interview in 
1987 and 1991 makes it possible to see some of the changes that took place. Of the 17 followup respondents who in 1987 reported no use of cocaine in the 3 months prior to interview, four had resumed their use, three at a low level. None of these 17 reported medium or high levels of use at the time of the follow-up interview. Of the 41 follow-up respondents who used at a low level 3 months prior to the 1987 interviews, 27 report no use during the 3 months prior to the 1991 interviews, 13 remained at low levels of use, and one person moved from a low to a medium level of use by 1991. Development to high level of use did not occur. Of the five persons who reported medium level use in 1987, two remained at medium levels and three moved down to low levels by 1991 (Table 16). This means that of the 64 persons we interviewed, just four persons $(6 \%)$ moved to a level of use higher than they reported in 1987. Twenty nine (45\%) remained at the same level (nonuse included) and 27 (42\%) moved to a lower level of use (nonuse included). This suggests that at least for this group of experienced cocaine users, stable or decreasing use patterns were the norm, with very few reporting a pattern of increasing use in the four years between 1987 and 1991.

\begin{tabular}{|c|c|c|c|c|c|c|c|c|}
\hline \multirow{3}{*}{$\begin{array}{l}\text { level of use } \\
\text { in } 1987\end{array}$} & \multicolumn{8}{|c|}{ level of use in 1991} \\
\hline & \multicolumn{2}{|c|}{ none } & \multicolumn{2}{|c|}{ low } & \multicolumn{2}{|c|}{ medium } & \multicolumn{2}{|c|}{ total } \\
\hline & $\mathrm{n}$ & $\%$ & $\mathrm{n}$ & $\%$ & $\mathrm{n}$ & $\%$ & $\mathrm{n}$ & $\%$ \\
\hline none & 14 & 82 & 3 & 18 & - & - & 17 & 100 \\
\hline low & 27 & 66 & 13 & 32 & 1 & 2 & 41 & 100 \\
\hline medium & - & - & 3 & 60 & 2 & 40 & 5 & 100 \\
\hline total & 41 & 65 & 19 & 30 & 3 & 5 & 63 & 100 \\
\hline
\end{tabular}

When we compare top levels of use prior to 1987 and during the period from 1987-1991 an important finding emerges. Here the same dynamics of decreasing levels are apparent. For six respondents the top level of consumption increased (from low to medium), but for the majority the top level either remained constant (low for 14 respondents), or decreased (13 respondents)..$^{20}$

Career data on all 64 follow-up respondents are presented in Figure 2 for five periods of use. This figure shows substantial shifting of use levels over 5 periods in the career of all 64 followup respondents. These five periods are initial year of regular use, period of heaviest use before interview in 1987, last three months prior to interview in 1987, one year prior to follow-up in 1991 and last three months prior to follow-up. These five periodd span a cocaine consumption career of about ten years since first regular use (12 years since initiation).

As in 1987, the main method of use among our follow-up respondents remained snorting. Since 1987, 27 of the 34 nonabstinent follow-up respondents $(79.4 \%)$ reported they had snorted almost without exception. Seven had used one or more other methods: injection (once for 1 person), eating (four persons once, 1 person "always," and two others occasionally). Five respondents reported that on rare occasions they had applied cocaine to their genitals, and three respondents had on rare occasions freebased. Two persons mainly smoked cocaine in handmade cigarettes, and 24 others had experience with smoking cocaine at least once.

We asked each of our 34 nonabstinent follow-up respondents about the advantages and disadvantages they perceived in different modes of ingestion. They offered many opinions, but here we refer only to those regarding injecting and freebasing. All 34 had an opinion on 
Figure 2. Level of cocaine use over time (number of respondents between brackets, $N=64$ )

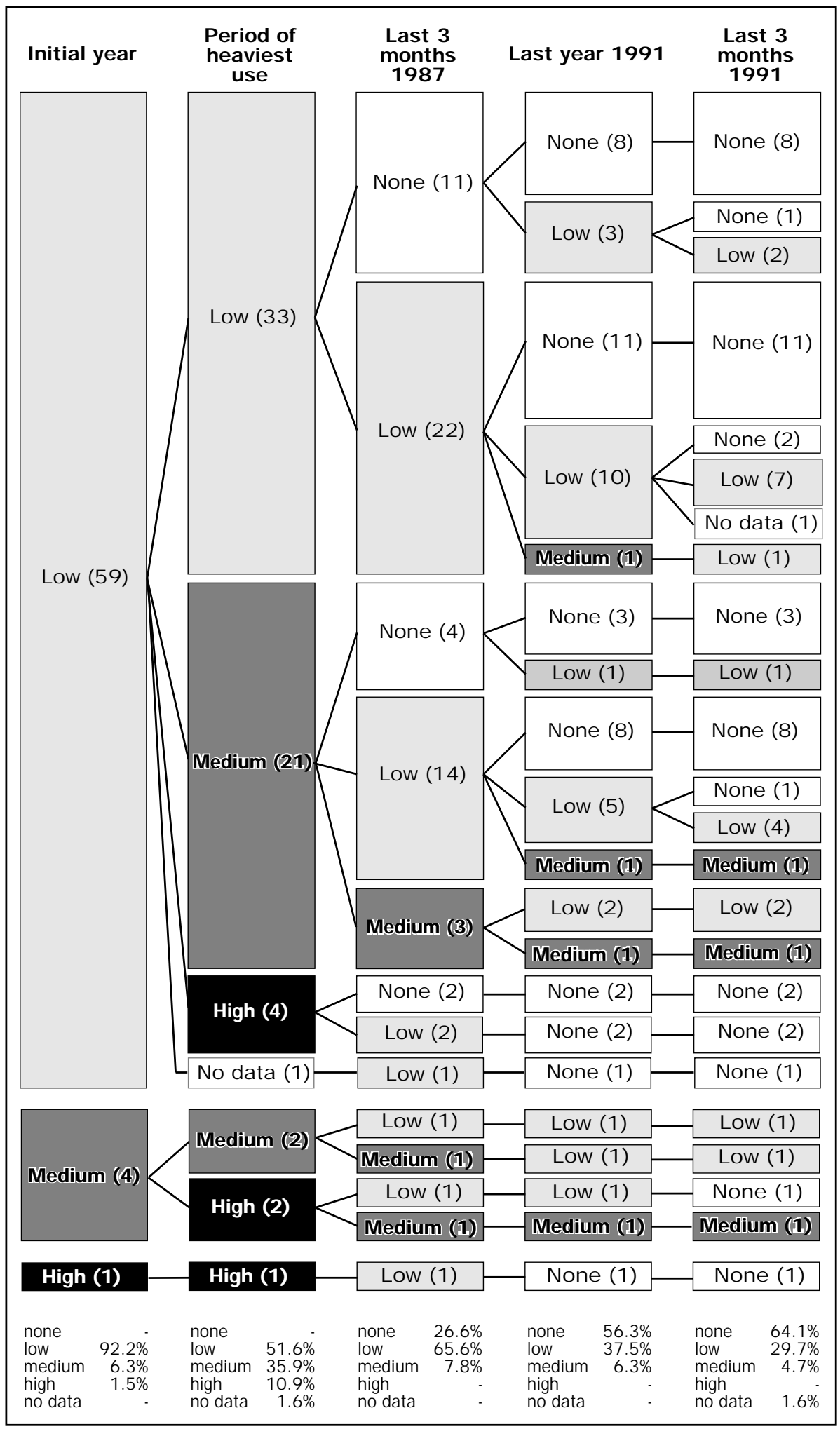


injecting, some more than one. Altogether they mentioned 39 perceived advantages of injection and 59 perceived disadvantages. The most frequently mentioned perceived advantage of injection was the better effect and/or "the flash" (22 times). The most often mentioned perceived disadvantage was that injection is unhealthy and/or dangerous ( 21 times). The next most often mentioned disadvantage had to do with the image of injection: "it is addicting" and/or "like junkies do" (18 times).

Interestingly, in spite of the fact that many respondents believed that the effects of injection were better than those of snorting, actual experience with injecting remained rare because of the perceived risks. This perception about injection risks may be seen as an important informal control to which most of our respondents held strongly throughout the follow-up period. Almost the same holds for freebasing. Nearly all of our nonabstinent follow-up respondents (33 of 34) noted advantages of freebasing as a method of ingestion, of which better effects was the most commonly mentioned (24 times). Yet the related disadvantage that freebasing is addicting or is something "like junkies do" was mentioned almost as often (23 times). Six said freebasing was too expensive and six thought it was too complicated or messy.

In short, our follow-up respondents perceived numerous advantages and disadvantages of various modes of ingestion and chose the one that they considered both safe and not associated with groups perceived as deviant. While many experimented with other modes, they generally did not stick to methods they perceived as more pleasurable but also as more risky and deviant. We cannot exclude the possibility that these users absorb many social constructions about drugs just as everyone else. "Normal" aversion against injection and its modern association with 'junkie behavior,' and sensitivity to mass media images about crack are probably as prevalent with these snorting cocaine users as with nonusers.

\section{Price and Quality of Cocaine}

The price of cocaine in Amsterdam appears to have decreased and quality increased between 1987 and 1991. This finding applies only to the market segment of the users we investigated. According to the 28 follow-up respondents who answered our question about the current cost of cocaine, the mean and median price per gram in 1991 was fl 149 (\$81). In 1987, the mean price was fl 180 (\$100). Just over 50\% of the respondents had paid over fl 200 per gram in 1987. In 1991 , only $15 \%$ had paid such a price.

We were able to buy 9 cocaine samples from 34 nonabstinent follow-up respondents in 1991. These samples were analyzed in the central Laboratory of the Municipal Police in Amsterdam, ${ }^{21}$ yielding an average cocaine hydrochloride purity of $87 \%$, with a range between $74 \%$ and $96 \%$. In 1987 we found an average purity of $65 \%$ with 39 samples with a range between $14 \%$ and $90 \%$.

\section{Settings of Cocaine Use}

In 1987 we found that the most important settings for cocaine use were "going out," "going to parties" and "social gatherings with friends." We asked about settings again in 1991 to see if there had been any such shift in the overwhelmingly social contexts of cocaine use for our follow-up respondents. We found none. The same three settings were reported as by far the most important.

Situations in which respondents felt it best not to use also had not changed. The four most often mentioned ones in 1987 were 'work and study' situations, 'before some kind of achievement,' in 'daily life' situations, and 'with nonusers.' These four situations were reported in exactly 
the same rank order in 1991 by 33 of our 34 non-abstinent respondents. These data, too, suggest that the subcultural functions of cocaine use have remained very stable among our respondents. The fact that most of these 34 experienced users had decreased their levels of use considerably seemed to have no effect upon the uses to which cocaine was put.

Emotional sets played some role in cocaine consumption in 1987. In 1991, similarly, 19 out of 34 respondents said that certain emotional states could provoke their desire to use cocaine. As in 1987, "joy" or "feeling very well" was the most often mentioned ( $25 \%$ of all answers in 1987, $29 \%$ in 1991). This was in keeping with the predominantly social functions that cocaine served for these respondents. Next in importance was "feeling tired" (20\%). Many other emotional states were mentioned by very small numbers of respondents.

\section{Rules of Use}

Those who claim that cocaine is inherently addictive sometimes cite experiments with caged rats and monkeys who had unlimited access to unlimited supplies of cocaine and nothing else to do. Although such conditions virtually never exist for humans, our follow-up respondents (as did all our other respondents) had very easy access to cocaine-culturally and geographically. Financial access is not much of a problem, although income level generates its own limits. Therefore, if addiction were strictly a function of the physiological presence of and access to the substance, we would expect to find many long-term, frequent cocaine users exhibiting patterns of use we associate with addiction. As shown in our data on development of use patterns in our follow-up respondents, this was not the case.

\section{Advice to Novice Users}

We asked about "rules" of use in many different ways. ${ }^{22}$ One was that we invited the nonabstaining respondents to give advice to novice users on route of ingestion, dosage, situations, combinations with other drugs and buying cocaine. Clearly snorting is the route of ingesting these experienced cocaine users want novices to practice. This shows that route of ingestion (i.e. stay with snorting) serves as a control mechanism for these users: "snort only" was the advice of 24 out of 34 (71\%) of our nonabstinent follow-up respondents. Two respondents advised that novices avoid injecting, and two others advised snorting or else smoking (via cigarette). Only one respondent said that one can use any amount, and one other advised simply to use "enough." All the others advised that doses be limited in some way: "not too much, not more than..., just a little." When we asked about conditions of use, we received exactly the same answers we got when we asked respondents about situations fit for cocaine use: use in good company and be sure that you feel good already. Only two persons said that conditions of use were unimportant. When we asked respondents in 1987 if they had advice for novices about buying cocaine, $20 \%$ said they should always buy from one steady dealer. In the 1991 follow-up, however, only two persons gave such advice. But while buying from a single dealer no longer seemed very important, the 1991 answers indicate that not buying in public places like discos or on the streets is important. The proportion giving this response increased from 15\% in 1987 to $40 \%$ in 1991. Unchanged from 1987 to 1991 was the most frequently given advice about buying - the desirability of going to a reliable person. 


\section{Conclusions}

To judge from this summary of rules that are recognized by cocaine users, we might infer that control mechanisms are very much in line with the dominant modes and levels of use in this group. From the relative absence of destructive and compulsive use patterns over a ten year period, we may conclude that users can and do exercise control. Our respondents applied two basic types of controls to themselves: 1) restricting use to certain situations and to emotional states in which cocaine's effects would be most positive, and 2) limiting mode of ingestion to snorting of modest amounts of cocaine, staying below 2.5 grams a week for some, and below 0.5 grams a week for most. Nevertheless, those whose use level exceeded 2.5 grams a week all returned to lower levels.

Neither of these forms of user control appeared to rely on external social control agencies, although it remains unclear if price of cocaine plays a role. ${ }^{23}$ Quite probably the enormous increase in prevalence of adverse cocaine effects for use levels over 2.5 gram a week works as a physical control for high level users. A number of negative cocaine effects cannot be escaped by any user. Since most of these users are socially fully integrated, cocaine consumption has to find its niche among many other activities and goals of these users (cf. Waldorf et al., 1991; Reinarman et al., this issue). Since cocaine use has such strong social functions, dysfunctional consequences disrupt the very reasons of use. Some take some time to learn this, but our data show that most do. ${ }^{24}$

Of course, such external social controls as law enforcement are present in Amsterdam, but were not seen as relevant by half of our respondents. The other half reported that their cocaine use was influenced by current laws and policies, but this influence was equally divided between positive and negative. All nonabstinent follow-up respondents had a range of cocaine dealers to choose from, and cocaine buying, typically in apartment houses, presented no risk..$^{25}$ Nonabstinent follow-up respondents earn enough money to buy cocaine (average net monthly income fl 2971).

Our data directly contradict the physiological models under girding current law. For example, Gawin (1991) states:

Limitation on drug access, including the high price of cocaine and legal limitations on distribution, regulate human cocaine use and may prevent human cocaine use from more frequently mimicking animal free-access experiments in producing death.

In our follow-up sample, drawn from the much larger pool of users outside the treatment population, only 4 of our 64 respondents had ever considered seeking treatment, only one of whom actually did so (for combined heavy alcohol use with medium level cocaine use). This means that under the low external control conditions prevailing for our respondents, $6 \%$ had negative subjective experiences of cocaine abuse, sufficient to move them to start thinking about treatment. Thus, we may safely infer that reliance on self-regulatory or informal social controls was what prevented the great majority of these users from succumbing to the risks of cocaine abuse, rather than institutional, external law enforcement type of control.

The evidence from our limited follow-up sample cannot, of course, fully refute claims that large proportions of humans who use cocaine regularly will over time progress to heavy use and addiction. For such refutation to be conclusive, there would have to be repeated longitudinal measurements of use patterns in many different settings. But these Amsterdam 
data do demonstrate that extended careers of cocaine use, lasting even a decade, do not inevitably culminate in compulsive and/or destructive use or "addiction." When viewed in combination with similar findings from other studies of non-treatment samples such as Erickson et al.'s $(1987,1992)$ in Canada and Murphy et al.'s (1989) in California, our data cast serious doubts on the validity of claims that cocaine use generally eventuates in abuse and addiction.

\section{References}

CoHen, P.D.A. (1989) Cocaine Use in Amsterdam in Non Deviant Subcultures. Amsterdam: Instituut voor Sociale Geografie, Universiteit van Amsterdam

¿COHEN, P.D.A. \& SAS, A.J. (1992) Loss of control over cocaine, rule or exception. Paperpresented at

the American Society of Criminology, New Orleans, USA, November 3-7, 1992

COHEN, P.D.A. \& SAS, A.J. (1993) Ten Years of Cocaine. A Follow-up Study of 64 Cocaine Users in

Amsterdam. Amsterdam: Instituut voor Sociale Geografie, Universiteit van Amsterdam

COHEN, P.D.A. \& SAS, A.J. (forthcoming) Cocaine Use in Amsterdam II. Initiation and Patternsof

Useafter 1986. Amsterdam: Instituut voor Sociale Geografie, Universiteit van Amsterdam

ERICKSON, P. (1992) A Longitudinal Study of Cocaine users: The Natural History of Cocaine UUseand its Consequences among Canadian Adults. Toronto: Addiction Research Foundation. Final Report NHRDP \# 6606-3929-DA

Erickson, P.E. Adlaf, Murray, G. \& Smart, R. (1987). The Steel Drug: Cocaine in Perspective. Toronto: Lexington Books

GAWIN, F. (1991), Cocaine addiction: Psychology and neurophysiology. Science, 251, 1580-1586

Hartnoll, R. (1990), Non pharmacological factors in drug abuse. Behavioural Pharmacology, 375-384

Lindesmith, Alfred R. (1968) Addiction and Opiates (revised 1947 Edition). Chicago

MOKKEN, R.J. \& LEWIS, C. (1982) A non parametric approach to the analysis of dichotomousitem responses. Applied Psychological Measurement, 6, 417-430

Morningstar, P. \& Chitwood, D. (1983) The patterns of cocaine use. An interdisciplinary study. Final Report. Rockville: National Institute on Drug Abuse

Murphy, S, ReinARMAn, C. \& WALDORF, D. (1989) An 11 year follow up of a network of cocaineusers. British Journal of Addiction, 84, 427-436

Reinarman, C., Murphy, S. \& Waldorf, D. (1994) Pharmacology is not destiny: Thecontingent character of cocaine abuse and addiction. Addiction Research.

SANDWIJK, J.P., WeSterterP, I. \& Musterd, S. (1988) Het gebruik van legale en illegale drugsin Amsterdam. Amsterdam: Instituut voor Sociale Geografie, Universiteit van Amsterdam

SANDWIJK, J.P., COHEN, P.D.A. \& Musterd, S. (1991), Licit and Illicit Drug Use in Amsterdam.Report of a Household Survey in 1990 on the Prevalence of Drug Use among the Population of 12 Years and Over. Amsterdam: Instituut voor Sociale Geografie, Universiteit van Amsterdam

Sijtsma, K. \& Verwey, A.C. (1992) Mokken scale analysis; theoretical considerations and anapplication to transitivity tasks. Applied Measurement in Education, 5 (4), 355-373

Waldorf, D., Reinarman, C. \& Murphy, S. (1991) Cocaine Changes. Philadelphia: Temple University Press 


\section{Notes}

1 We allowed our snowballs to self direct themselves into deviant circles if this occurred.

2 Primarily heavy opiate users who also use cocaine.

3 We wanted to prevent unknown nominee preferences from biasing respondent selection.

4 Lifetime prevalence of cocaine use in the household population sample of 12 years and older $(\mathrm{N}=4,371)$ was $5.6 \%$ in 1987 (Sandwijk et al., 1988). In 1991, the LTP of cocaine use $(\mathrm{N}=4,440)$ was $5.3 \%$ (Sandwijk et al., 1991).

5 Writers, painters, film producers, all kinds of advertisement people, graphics artists.

6 Dutch $\mathrm{fl}=\$ 0.5$, ú 0.4

7 Of 50 high level users at top period, $12(24 \%)$ were abstinent at time of interview. Of 82 medium level users at top period, 23 (28\%) were abstinent at interview. Of 134 low level users at top period, $27 \%$ were abstinent at the time of the interview.

8 Median values are mentioned here because of the enormous range of typical dosages. A few very high dosage users can change average values considerably in the upward direction, which is the reason medians give a better idea of central tendency here.

9 Crack, a commercial form of freebase smokable cocaine was not mentioned by our respondents. Although we did not explicitly ask for crack use in our interviews, we are quite sure that if crack use had occurred it would not have escaped us.

10 Comparability was limited because sampling, entry criteria and definitions of level of use were dissimilar. With this in mind we found that of 41 common effect questions, 27 effects were related to some parameter of use in all three studies; 14 effects show no consistency among the studies.

11 Mokken scale analysis is based on Guttman scale analysis. The latter however is deterministic, which means that a respondent who answers an item in a positive way must answer less difficult items also in a positive way. Mokken analysis is probabilistic, meaning that a respondent answering an item positively has a significantly greater probability than null to answer a less difficult item in a positive way as well (Mokken et al., 1982, Sijtsma et al., 1992).

12 In other words, the pharmacology of cocaine is one thing, but the psychological and social system in which is used by humans is not unimportant (cf. Hartnoll, 1990).

13 A good theory of drug effects would have to be developed first. Providing such theory is probably one of the most difficult challenges of drug research.

14 The reason why we did not compare snorters with injectors only or freebasers only is that the latter categories were too small for meaningful comparison. The solution we chose, almost exclusively snorters versus all users, has the advantage that in the latter group even rare experience with other routes of ingestion than snorting is included.

15 We did not ask for details of these effects. One of our problems is whether effects were induced by cocaine only, or by mixtures of drugs. Cocaine is often taken with alcohol, and concomitant use of MDMA and cannabis is not uncommon.

16 We performed this analysis in 1989 only for our 1987 respondents.

17 No respondent was refused if he or she was not willing to provide a full set of identification data. Interviewers were not instructed to secretly write down these details. We were surprised that under 1987 conditions of cocaine policy still $30 \%$ of our respondents preferred to remain anonymous.

18 Two young homosexuals died of AIDS and one middle aged academic who lived on health insurance benefits, of heart disease.

19 Of 30 nonusers, 23 had used between one and ten times during the follow-up period. Seven respondents reported zero use.

20 We have no reliable top level data for 1987 for one respondent.

21 The Police and Public Prosecutor made our investigations possible by cooperating wholeheartedly. For instance, a written guarantee was provided that our data would not be seized. We considered this guarantee vital to insure complete safety to our respondents and interviewers. The investigator and one assistant were allowed to bring the cocaine samples (that we bought from respondents for 
fl 50) to the police laboratory where, after analysis, they were destroyed.

22 We specifically asked if respondents had any rules they tried to follow and we asked questions about rules in many other ways, e.g. with whom they would and would not use; when they would use and not use, etc.

23 When asked if a lower price of cocaine would influence their use level, 27 out of 34 nonabstinent follow-up respondents said this would have no influence. Six affirmed that if prices dropped by about $50 \%$, this would have an influence on their use level.

24 For some, this learning phase entails some tough lessons that may be very dangerous. Harm reduction policies might be advanced if this learning phase could be studied from the perspective of prevention. Some of the tough lessons are unnecessary. For most cocaine users studied here, prevention efforts directed to abstention would have been totally useless. But prevention efforts directed towards safer use and prevention of 'tough and dangerous lessons' would be useful.

25 Police concentrates its law enforcement efforts on large scale dealing and transit transaction. Low level individual dealers are left untouched as long as they remain inconspicuous. 